\title{
SEM Evaluation of Various Intracanal Irrigation Devices on Smear Layer Removal: A Comparative Study
}

\author{
Abhinav K Singh ${ }^{1}$, Shafait U Khateeb ${ }^{2}$, Sonia P Pathrose ${ }^{3}$, Aparna S Kumar ${ }^{4}$, Sengodan Haribaskar ${ }^{5}$, Gunaranjan Thota ${ }^{6}$
}

\begin{abstract}
Aim: The present study aimed at assessing the effectiveness of different intracanal irrigation devices on the removal of the smear layer. Materials and methods: The recently extracted 80 lower premolars having single canal were chosen for this in vitro study. A round diamond bur was used to gain endodontic access and the root canal was entered with a \#15 K-file until the tip was just seen at the apical foramen. Manual instrumentation of root canals of all teeth was done using the step-back method. The samples were later divided randomly into four groups. Later, each sample was exposed to final irrigation by using four different irrigation systems, group 1: conventional needle irrigation, group 2: irrigation with ultrasonic activation, group 3: irrigation with EndoVac system activation, group 4: irrigation with EndoActivator. The samples were next mounted and visualized under scanning electron microscope (SEM) for the absence or presence of the smear layer.

Results: Irrigation with EndoVac system activation showed the presence of least smear layer $(2.40 \pm 0.32)$, followed next by EndoActivator $(3.24 \pm 0.46)$ and ultrasonic activation $(4.96 \pm 0.54)$ and conventional needle irrigation $(5.20 \pm 0.10)$. No statistically significant difference was found in the apical and coronal thirds of the root canal in removal of the smear layer on an intragroup comparison. However, a statistically significant $(p<0.001)$ difference was seen between the groups at the apical and coronal thirds on an intergroup comparison.

Conclusion:This study demonstrated the EndoVac system group to be efficient in removal of the smear layer when compared to the EndoActivator system, ultrasonic activation, and conventional needle irrigation group.

Clinical significance:The definitive objective of endodontic therapy is to transform the affected teeth to a healthy and functional state. The irrigants can reach the working length when delivered by an effective irrigation delivery system. This type of delivery system should deliver adequate volume of irrigants all the way up to the working length and have sufficient flow and be efficient at debridement of complete canal system.

Keywords: Irrigation, Root canal, Scanning electron microscope, Smear Layer.

The Journal of Contemporary Dental Practice (2021): 10.5005/jp-journals-10024-3002
\end{abstract}

\section{INTRODUCTION}

A thorough cleaning and decontamination of the canals is necessary to ensure a complete obturation, and this determines the success of root canal therapy. The smear layer is an asymmetrical unstructured layer composed of inorganic materials and organic components, such as necrotic debris, odontoblastic process, pulp tissue, microbes, and their metabolic products. This layer is present only on the dentinal walls of the root canals which are instrumented. ${ }^{1}$

If this smear layer remains unremoved during the last stage of irrigation, then the root canal therapy fails. The smear layer adheres to the instrumented dentinal walls and may act as a pool for microbes. Thus, it blocks the dentinal tubules and avoids entry of the disinfectants and prevents the bonding with the root canal filling materials. ${ }^{2}$

The efficiency of root canal irrigation is based on many factors including the rate of flow, action of flushing, fluid dynamics, and kind of device used to perform irrigation. It also depends on the root canal anatomy like the occurrence of sulci, curvatures, isthmuses, and ramifications; steps in instrumentation which help to obtain a suitable canal shape and efficient cleansing by files; and chemical composition of the root canal irrigants, e.g., their volume, fluid properties, antibacterial and chelating potential, and efficiency to dissolve the tissues chemically. ${ }^{3}$

In 1957, ultrasound was introduced to endodontics by Richman for debridement of the canal. But, the ultrasonic devices were being used in periodontics much before this. When compared to sonic energy, ultrasonic energy produces high frequencies, coupled
${ }^{1}$ Department of Conservative Dentistry and Endodontics, Buddha Institute of Dental Sciences and Hospital, Patna, Bihar, India

${ }^{2}$ Department of Restorative Dental Sciences, College of Dentistry, King Khalid University, Abha, Kingdom of Saudi Arabia

${ }^{3}$ Department of Conservative Dentistry and Endodontics, Mar Baselios Dental College, Kothamangalam, Kerala, India

${ }^{4}$ Department of Prosthodontics, Sri Ramakrishna Dental College and Hospital, Coimbatore, Tamil Nadu, India

${ }^{5}$ Department of Conservative Dentistry and Endodontics, Sri Ramakrishna Dental College and Hospital, Coimbatore, Tamil Nadu, India

${ }^{6}$ Department of Restorative Dental Sciences, College of Dentistry, Majmaah University, Az-Zulfi, Kingdom of Saudi Arabia

Corresponding author: Abhinav K Singh, Department of Conservative Dentistry and Endodontics, Buddha Institute of Dental Sciences and Hospital, Patna, Bihar, India, Phone: +91 9576969374, e-mail: akspat01@gmail.com

How to cite this article: Singh AK, Khateeb SU, Pathrose SP, et al. SEM Evaluation of Various Intracanal Irrigation Devices on Smear Layer Removal: A Comparative Study. J Contemp Dent Pract 2021;22(2): 184-188.

Source of support: Nil

Conflict of interest: None

with small amplitudes. The endodontic files are made to oscillate at $25-30 \mathrm{kHz}$ ultrasonic frequency. ${ }^{4}$

(0) Jaypee Brothers Medical Publishers. 2021 Open Access This article is distributed under the terms of the Creative Commons Attribution 4.0 International License (https://creativecommons.org/licenses/by-nc/4.0/), which permits unrestricted use, distribution, and non-commercial reproduction in any medium, provided you give appropriate credit to the original author(s) and the source, provide a link to the Creative Commons license, and indicate if changes were made. The Creative Commons Public Domain Dedication waiver (http://creativecommons.org/publicdomain/zero/1.0/) applies to the data made available in this article, unless otherwise stated. 
EndoActivator consists of a transportable handpiece and three different types of flexible disposable tips made up of polymer and the irrigants get sonically activated. This setup does not cut the root dentin. Cavitation and aural streaming interrupt the biofilm and the smear layer and improve the debridement significantly. When compared to various other irrigation devices, the EndoActivator appears to have a negligible amount of irrigant extrusion from the apex, and the incidence of extrusion depends on the size of

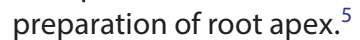

Recently, an EndoVac system was showcased and it is one among the irrigation systems which creates a negative apical pressure. The objective of this system is to deliver an effective and safe canal cleaning, particularly in the apical portion of the root canal. It is fabricated for debris removal under suction and to distribute the irrigation solutions in the apical third of the root canals. Conventional irrigation with needle is the standard procedure but unfortunately, it is not effective in the apical third of the root canal and in the isthmuses or oval extensions. ${ }^{6}$ There are very limited data in the literature comparing the root canal irrigant systems for smear layer removal. Therefore, this in vitro study aims to compare and assess the efficacy of four different endodontic irrigation systems in removal of the smear layer present within the root canals with the help of a scanning electron microscopy (SEM).

\section{Materials and Methods}

\section{Sample Selection and Preparation}

The present in vitro study was conducted in the Department of Conservative Dentistry and Endodontics, Buddha Institute of Dental Sciences and Hospital, Patna, and this study was conducted in October 2019. Totally 80 recently extracted lower premolars having single canal were chosen for the study. The reason for extraction was for orthodontic purposes or due to unhealthy periodontal conditions. A hand scaler was used to debride the external teeth surfaces. The nail varnish was later used to seal the apices of the teeth to stop the escape of irrigating solution through the apical foramen. Until further use, all teeth were kept at room temperature in physiological saline.

Single-rooted, completely formed teeth with completely patent canal and intact apices, with no multiple roots, open apices, caries, and root canal fillings, were chosen for this study. Tooth with anatomical variations, canal calcifications, fractured roots, root resorption, and cracks on the surface were excluded from the study.

A round diamond bur was used to gain the endodontic access and a \#15 K-file (Dentsply Maillefer, Ballaigues, Switzerland) was inserted into the root canal until the tip was just seen at the foramen. Deduction of $1 \mathrm{~mm}$ from the length of the files which were stopped just outside the apical foramen gave the working lengths. A diamond disc was used to section the crowns in order to get a $16-\mathrm{mm}$ standard working length for all the teeth. The apices were closed with a hot glue to produce clinical conditions.

Manual instrumentation using the step-back method was done for 80 root canals. Manual canal instrumentation was initially done with the use of K-files equal to \#40 master apical size in addition to irrigation with $5.25 \% \mathrm{NaOCl}(5 \mathrm{~mL}$ ). A \#45 K-file was used to start the apical third step back phase, followed by sequential use of five larger K-files up to \#70. A complete endodontic procedure was carried out by a single investigator, and blinding procedure was followed. The samples were randomly divided into four groups. Later, each sample was exposed to final irrigation by means of four irrigation systems.

\section{Group 1: Conventional Needle Irrigation}

The canals were flushed for 1 minute with $1 \mathrm{~mL}$ of normal saline followed by use of $5 \% \mathrm{NaOCl}(3 \mathrm{~mL})$ for canal flushing.

\section{Group 2: Irrigation with Ultrasonic Activation}

An ultrasonic, passive activation of the irrigants was done finally using mini Piezon ultrasonic irrigation system (EMS, Nyon, Switzerland), along with \#20 ultrasonic files (Satelec, Acteon, Merignac, France). The ultrasonic file was inserted into the canal at $1 \mathrm{~mm}$ less than the working length with no contact with the walls and was started at 4 power setting.

\section{Group 3: Irrigation with EndoVac System Activation}

The EndoVac system (EndoVac, Discus Dental, Culver City, CA, USA) using microcycles was used to irrigate the canals. The microcannula was positioned at the working length and was later continuously repositioned $2 \mathrm{~mm}$ up and down in the canal. The first cycle of this constant active irrigation was performed using $5 \% \mathrm{NaOCl}(4 \mathrm{~mL})$. A second passive cycle followed the active irrigation with $5 \% \mathrm{NaOCl}$ (4 mL).

\section{Group 4: Irrigation with EndoActivator}

Irrigant activation was done using EndoActivator (Dentsply Sirona, $\mathrm{GmbH}$, Bensheim, Germany) with a tip size of 35/04. The tip was entered up to $2 \mathrm{~mm}$ less than the working length into a canal which was flooded before with the irrigant and was activated for a period of 30 seconds. Saline solution was used to wash the canal, and paper points were used to dry them. Additional turn of activation was performed.

Later, final irrigation of the root canals was done with distilled water $(5 \mathrm{~mL})$ to eliminate any precipitate. Sterile paper points were then used to blot dry the canals and a cotton pellet (sterile) was kept and the access cavity was closed.

\section{Sample Preparation for SEM Evaluation}

Grooves were made longitudinally using a slow-speed diamond disc on the lingual and buccal surfaces of each root with no penetration of root canal. The roots were later sectioned into two halves and were stored at $37^{\circ} \mathrm{C}$ in deionized water until analysis by a SEM. A $100 \%$ ethyl alcohol solution was used to dehydrate the specimens and was kept in a furnace for 24 hours at $60^{\circ} \mathrm{C}$. Metallic stubs were used to mount the samples and visualized under SEM (LEO 440i, Carl Zeiss, Tokyo, Japan) for the absence or presence of the smear layer at the coronal and apical thirds under $2000 \times$ magnification. The SEM images (Fig. 1) were separately scored by another examiner who was blinded to specimen groups using the criteria reported by Torabinejad et al. ${ }^{7}$ :

$1=$ No smear layer. No smear layer on the root canal surface; all tubules were open and clean.

$2=$ Moderate smear layer. Absence of smear layer on the root canal surface, but debris is present within the tubules.

3 = Heavy smear layer. Presence of smear layer on the root canal surfaces and tubules.

\section{Statistical Analysis}

A version 20 statistical package for social sciences (SPSS) (SPSS Inc., Chicago, IL, USA) was used to analyze the data. Kruskal-Wallis tests were used to evaluate the significant difference. A $p$-value of $<0.05$ was considered to be statistically significant. 

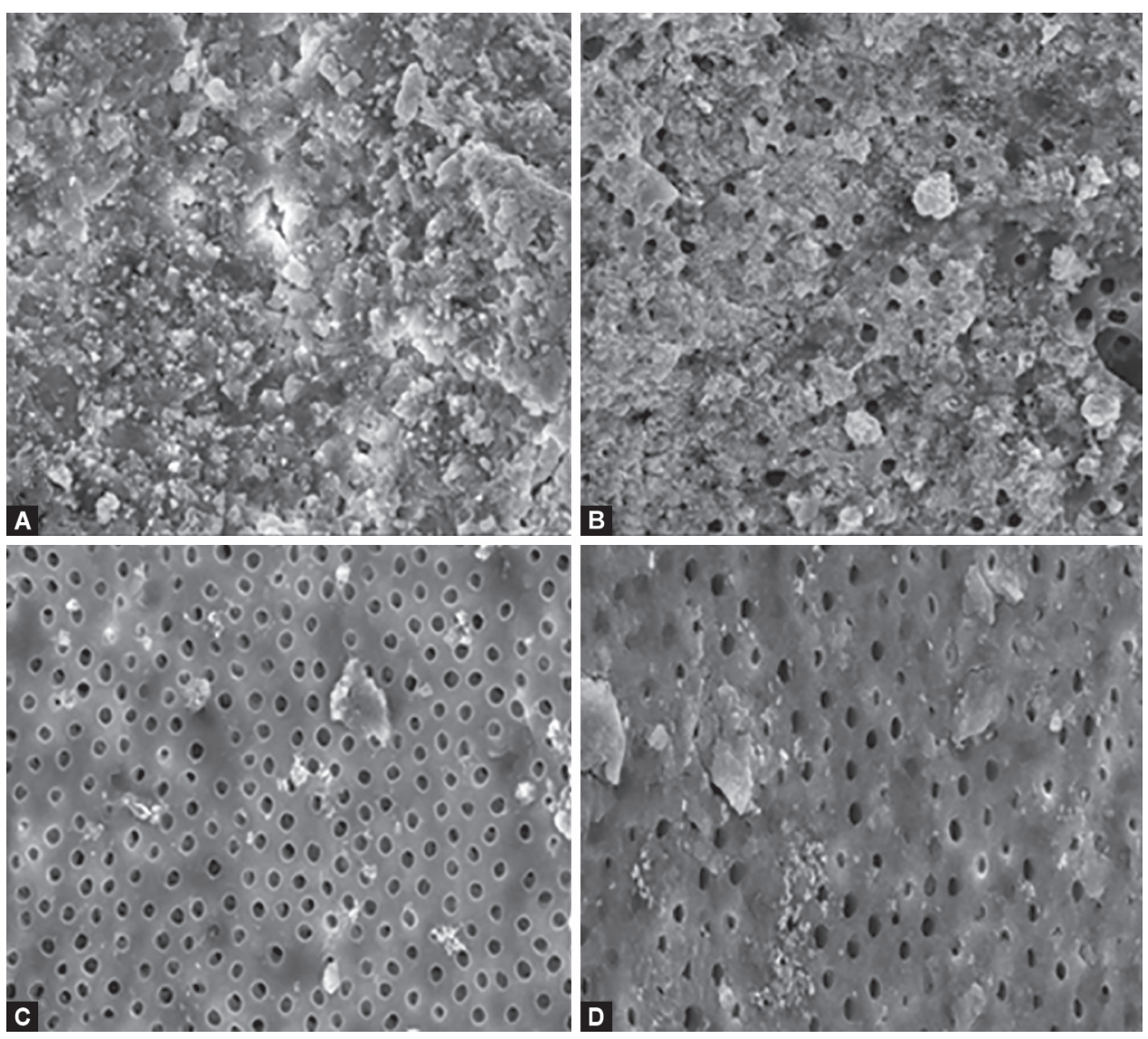

Figs. $1 \mathrm{~A}$ to D: SEM images of (A) Conventional needle, (B) Ultrasonic activation, (C) EndoVac system activation, (D) EndoActivator

Table 1: Mean and standard deviation of four different irrigation device groups

\begin{tabular}{lll}
\hline Irrigation device groups & $N$ & Mean \pm standard deviation \\
\hline $\begin{array}{l}\text { Group 1: conventional } \\
\text { needle irrigation (control) }\end{array}$ & 20 & $5.20 \pm 0.10$ \\
$\begin{array}{l}\text { Group 2: irrigation with } \\
\text { ultrasonic activation }\end{array}$ & 20 & $4.96 \pm 0.54$ \\
$\begin{array}{l}\text { Group 3: irrigation with } \\
\text { EndoVac system activation } \\
\text { Group 4: irrigation with }\end{array}$ & 20 & $2.40 \pm 0.32$ \\
EndoActivator & 20 & $3.24 \pm 0.46$ \\
\hline
\end{tabular}

\section{Results}

Table 1 shows the mean and standard deviation of four different irrigation device groups. Irrigation with EndoVac system activation resulted in minimum smear layer $(2.40 \pm 0.32)$, trailed next by EndoActivator ( $3.24 \pm 0.46)$, ultrasonic activation ( $4.96 \pm 0.54)$, and conventional needle irrigation $(5.20 \pm 0.10)$.

The intragroup comparison of efficacy of smear layer removal by different irrigation devices at the apical and coronal levels is shown in Table 2. Higher scores were seen in group 1 (control group) compared to all three study groups at all locations $(2.88 \pm 0.08$ and $2.32 \pm 0.02)$. Group 3 showed a minimum mean score at the coronal and apical locations $(1.30 \pm 0.23$ and $1.10 \pm 0.03)$. However, there was no statistically significant
Table 2: Intragroup comparison of efficacy of smear layer removal by different irrigation devices at the coronal and apical levels

\begin{tabular}{lllll}
\hline $\begin{array}{l}\text { Types of irrigation } \\
\text { devices }\end{array}$ & $\begin{array}{l}\text { Coronal } \\
(\text { mean } \pm \text { SD) }\end{array}$ & $\begin{array}{l}\text { Apical } \\
\text { (mean } \pm \text { SD) }\end{array}$ & $\begin{array}{l}\text { KANOVA } \\
\text { value }\end{array}$ & $p$-value \\
\hline $\begin{array}{l}\text { Group 1: } \\
\text { conventional } \\
\text { needle irrigation } \\
\text { (control) }\end{array}$ & $2.88 \pm 0.08$ & $2.32 \pm 0.02$ & 28.10 & 0.084 \\
$\begin{array}{l}\text { Group 2: } \\
\text { irrigation with }\end{array}$ & $2.70 \pm 0.18$ & $2.26 \pm 0.36$ & 23.60 & 0.084 \\
$\begin{array}{l}\text { ultrasonic } \\
\text { activation }\end{array}$ & & & & \\
$\begin{array}{l}\text { Group 3: } \\
\text { irrigation with }\end{array}$ & $1.30 \pm 0.23$ & $1.10 \pm 0.03$ & 24.22 & 0.061 \\
$\begin{array}{l}\text { EndoVac system } \\
\text { activation }\end{array}$ & & & & \\
$\begin{array}{l}\text { Group 4: } \\
\text { Irrigation with }\end{array}$ & $1.43 \pm 0.30$ & $1.81 \pm 0.16$ & 24.84 & 0.068 \\
EndoActivator & & & & \\
\hline
\end{tabular}

difference in the efficacy on an intragroup comparison between the apical and coronal smear layer removal.

The intergroup efficacy of smear layer removal by different irrigation devices at the apical and coronal levels is shown in Table 3. A statistically significant $(p<0.001)$ difference was found between the groups at the coronal and apical thirds of the root canal. 
Table 3: Intergroup comparison of efficacy of smear layer removal by different irrigation devices at the coronal and apical levels

\begin{tabular}{lll}
\hline Types of irrigation devices & $\begin{array}{l}\text { Coronal } \\
(\text { mean } \pm S D)\end{array}$ & $\begin{array}{l}\text { Apical } \\
(\text { mean } \pm S D)\end{array}$ \\
\hline $\begin{array}{l}\text { Group 1: conventional } \\
\text { needle irrigation (control) }\end{array}$ & $2.88 \pm 0.08$ & $2.32 \pm 0.02$ \\
$\begin{array}{l}\text { Group 2: irrigation with } \\
\text { ultrasonic activation }\end{array}$ & $2.70 \pm 0.18$ & $2.26 \pm 0.36$ \\
$\begin{array}{l}\text { Group 3: irrigation with } \\
\text { EndoVac system activation }\end{array}$ & $1.30 \pm 0.23$ & $1.10 \pm 0.03$ \\
$\begin{array}{l}\text { Group 4: irrigation with } \\
\text { EndoActivator }\end{array}$ & $1.43 \pm 0.30$ & $1.81 \pm 0.16$ \\
K ANOVA value & 28.40 & 29.55 \\
$p$-value & 0.001 & 0.001 \\
\hline
\end{tabular}

\section{Discussion}

It is imperative that all the surfaces of the root canal wall, especially the apical part of the root canals, should come directly in contact with the irrigants for an effective action due to the typical complexity associated with the morphology of the root canals. There has to be an effective delivery system so that the irrigants can reach the apical portion. Several systems have been developed for an effective delivery of the irrigating solutions into the root canals. ${ }^{8}$

The technique of use of SEM which has been adapted in this study has often been used by others as well to assess the sanitation of the walls of the root canal after root canal instrumentation. Other studies $^{9,10}$ used a magnification of $50 \times$ to $2000 \times$ for root canal evaluation. We considered a 2000x magnification as it offers an advanced view and thorough image of the surfaces of the canal wall when compared to lower magnifications, thus permitting the identification of smear layer and debris, along with orifices of the tubules.

In this study, superior efficacy in terms of smear layer removal was shown by the EndoVac system than other groups. These results of obtaining clean canals could be attributed to a negative apical pressure created by the EndoVac system. Due to the negative apical pressure, the irrigant gets pulled down the walls of the canal up to the apex, thus forming a quick turbulent force of current toward the microcannula's terminus. The microcannula's orifices clear the debris from the closed apical end of the root canals. This mechanism allows for an effective irrigation by helping it to overcome the vapor lock. ${ }^{11}$ Our findings are in accordance with the results obtained by Saber and Hashem ${ }^{6}$ and Ribeiro et al. ${ }^{12}$ who also demonstrated a significant superiority of the EndoVac system in removal of debris from the apical portion of the root canal. Yet another study by Siu and Baumgartner ${ }^{13}$ demonstrated the EndoVac irrigation system to be significant in having less debris at $1 \mathrm{~mm}$ from the working length $(\mathrm{WL})$ in comparison with the conventional needle irrigation.

A more effective means of irrigation was achieved by Brunson et al. ${ }^{14}$ who delivered an increased volume of irrigating solution at the apical region. Even though the EndoVac system resulted in the lowest smear score in the apical third, it failed to achieve complete cleaning. The chief disadvantage of the EndoVac system is that some amount of irrigant escapes out of the canal before it reaches the apical region. So, near the apical third, there is a gradual decrease in the quantity of the cleaning solution that comes into contact with the canal wall. This may explain the reduced effect in the area of the apical third.
Next to the EndoVac system, the EndoActivator system demonstrated a better efficacy in terms of smear layer removal in the present study. These findings suggest an effective cleaning of debris from the lateral canals, deep entry of irrigants to all the endodontic spaces, dislodgement of biofilm-simulating clumps, and smear layer removal. A plausible description for obtaining clean canals due to irrigant activation is that increased frequency leads to an increased flow velocity which aids in efficient debris dislodgement. ${ }^{15}$ These findings are similar to those obtained by Jiang et al. ${ }^{15}$ These findings suggest that irrigant activation increases the dentinal debris removal from the apical third of the root canal. Its potential to generate sonic waves in the irrigating solutions which is within the root canal may help in bacterial killing and necrotic tissue debridement.

Ultrasonic irrigation was found to be better than the conventional needle irrigation in this study. This method depends on aural streaming arising from the passive tip for smear layer removal. It is mainly effective in teeth having straight canals. The passive file should not contact the canal walls and oscillate freely within the canal so as to achieve the highest effect from ultrasonic irrigation. ${ }^{16}$ Nevertheless, the unsuccessful results obtained, especially in the apical region, by this method, may be clarified by the intensity of ultrasonic activation. The least power intensity was used by this device. Jiang et al. ${ }^{17}$ have demonstrated an aligned increase in the cleaning efficiency with the ultrasonic activation output. The best cleaning results were reported in the set exposed to the highest output. These findings are not in accordance with the results obtained in the present study.

In the present study, the EndoVac system is significantly depicted as a better irrigation system in the removal of smear layer, which might be attributed to its negative apical pressure approach. The extent of effectiveness in the removal of smear layer from the root canals was different in each tested technique. This validates further studies employing better protocols for irrigation which support complete removal of debris from the apical portion of the canal.

\section{CONCLUSION}

This study demonstrated the EndoVac system group to be efficient in the removal of the smear layer when compared to EndoActivator system, ultrasonic activation, and conventional needle irrigation groups.

\section{References}

1. Torabinejad M, Handysides R, Khademi AA, et al. Clinical implications of the smear layer in endodontics: a review. Oral Surg Oral Med Oral Pathol Oral Radiol Endod 2002;94(6):658-666. DOI: 10.1067/ moe.2002.128962.

2. Violich DR, Chandler NP. The smear layer in endodontics-a review. Int Endod J 2010;43(1):2-15. DOI: 10.1111/j.1365-2591.2009.01627.x.

3. Boutsioukis C, Lambrianidis T, Kastrinakis E, et al. Measurement of pressure and flow rates during irrigation of a root canal ex vivo with three endodontic needles. Int Endod J 2007;40(7):504-513. DOI: 10.1111/j.1365-2591.2007.01244.x.

4. Gu L-s, Kim JR, Ling J, et al. Review of contemporary irrigant agitation techniques and devices. J Endod 2009;35(6):791-804. DOI: 10.1016/j. joen.2009.03.010.

5. Gadaalay S, Hariramani SI, Dhore $\mathrm{P}$, et al. Comparative evaluation of efficacy of three different irrigation activation systems in debridement of root canal isthmus: an in vitro study. Endodontology 2017;29(1):39-42. DOI: 10.4103/endo.endo_4_17.

6. Saber Sel-D, Hashem AAR. Efficacy of different final irrigation activation techniques on smear layer removal. J Endod 2011;37(9):1272-1275. DOI: 10.1016/j.joen.2011.06.007. 
7. Torabinejad M, Khademi AA, Babagoli J, et al. A new solution for the removal of the smear layer. J Endod 2003;29(3):170-175. DOI: 10.1097/00004770-200303000-00002.

8. Saini M, Kumari M, Taneja S. Comparative evaluation of the efficacy of three different irrigation devices in removal of debris from root canal at two different levels: an in vitro study. J Conserv Dent 2013;16(6):509-513. DOI: 10.4103/0972-0707.120959.

9. Goel S, Tewari S. Smear layer removal with passive ultrasonic irrigation and the NaviTip FX: a scanning electron microscopic study. Oral Surg Oral Med Oral Pathol Oral Radiol Endod 2009;108(3):465-470. DOI: 10.1016/j.tripleo.2009.04.023.

10. Zmener O, Pameijer $\mathrm{CH}$, Serrano SA, et al. Efficacy of the NaviTip FX irrigation needle in removing post instrumentation canal smear layer and debris in curved root canals. J Endod 2009;35(9):1270-1273. DOI: 10.1016/j.joen.2009.05.001.

11. Nielsen BA, Baumgartner JC. Comparison of the EndoVac system to needle irrigation of root canals. J Endod 2007;33(5):611-615. DOI: 10.1016/j.joen.2007.01.020.

12. Ribeiro EM, Silva-Sousa YT, Souza-Gabriel AE, et al. Debris and smear removal in flattened root canals after use of different irrigant agitation protocols. Microsc Res Tech 2012;75(6):781-790. DOI: 10.1002/jemt.21125.

13. Siu C, Baumgartner JC. Comparison of the debridement efficacy of the endovac irrigation system and conventional needle root canal irrigation in vivo. J Endod 2010;36(11):1782-1785. DOI: 10.1016/j. joen.2010.08.023.

14. Brunson M, Heilborn C, Johnson DJ, et al. Effect of apical preparation size and preparation taper on irrigant volume delivered by using negative pressure irrigation system. J Endod 2010;36(4):721-724. DOI: 10.1016/j.joen.2009.11.028.

15. Jiang $L M$, Verhaagen $B$, Versluis $M$, et al. Evaluation of a sonic device designed to activate irrigant in the root canal. J Endod 2010;36(1):143146. DOI: 10.1016/j.joen.2009.06.009.

16. Blank-Gonçalves LM, Nabeshima CK, Martins GH, et al. Qualitative analysis of the removal of the smear layer in the apical third of curved roots: conventional irrigation versus activation systems. J Endod 2011;37(9):1268-1271. DOi: 10.1016/j.joen.2011.06.009.

17. Jiang $L M$, Verhaagen $B$, Versluis $M$, et al. The influence of the ultrasonic intensity on the cleaning efficacy of passive ultrasonic irrigation. J Endod 2011;37(5):688-692. DOI: 10.1016/j.joen.2011.02.004. 